\title{
Effect of low dose IL-2 loaded chitosan nanoparticles on natural killer and regulatory $T$ cell expression in experimentally induced autoimmune type 1 diabetes mellitus
}

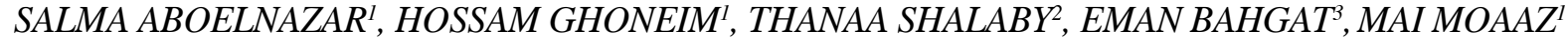 \\ ${ }^{1}$ Department of Immunology and Allergy, Medical Research Institute, Alexandria University, Egypt \\ ${ }^{2}$ Department of Biophysics, Medical Research Institute, Alexandria University, Egypt \\ ${ }^{3}$ Department of Pharmaceutics, Almaamora Hospital, Ministry of Health, Alexandria, Egypt
}

\begin{abstract}
Introduction: Natural killer cells (NK) initiate pancreatic islets cell lyses in autoimmune type 1 diabetes mellitus (TID). Loss of T regulatory cells (Treg) at disease onset facilitates activation and accumulation of NKs in the pancreatic microenvironment. A proper low dose interleukin 2 (IL-2) could enhance Tregs and enforce control and regulation of pro-inflammatory NKs. This relation needs to be studied to improve therapeutic strategies aimed at resetting the balance between Tregs and proinflammatory cells.

Material and methods: We used novel formulations of low dose IL-2 loaded on chitosan nanoparticles. The study included $116 \mathrm{TID}$ BALB/c mice experimentally induced by streptozotocin, divided into groups. Their splenocytes were maintained in a short-term culture for assessment of expression of $\mathrm{CD}^{+} \mathrm{Foxp}^{+}$ Treg and $N K p 46^{+} \mathrm{NK}$ by both flow cytometry and enzyme linked immunoassay (ELISA). In vitro suppressor-assay was used in order to assess the suppressor effect of Treg cells after exogenous IL-2 treatment.

Results: NK cell expression, NKp46 level and NK cell functions were modulated in mice injected with $I L-2$ loaded chitosan nanoparticles than other groups. A statistical inverse correlation was found between Treg and NK cell expression in IL-2 loaded chitosan with $(0.3 \mu I U)(p=0.047)$ and this correlation was related to Foxp3 expression on Treg cells. The modified expression of NK and NKp 46 was noticed in mice injected with $(0.3 \mu I U)$ for longer duration (three weeks) $(p<0.001)$ but the NK functions did not show any significant changes with prolonged treatment.

Conclusions: Low dose (0.3) $\mu I U$ IL-2 nanoparticles effectively modulated NK and NKp46 expression. It selectively modulates the suppressive activity of Tregs indicating a significant role of Tregs in NK activation and function by controlling the availability of IL-2 in the microenvironment.
\end{abstract}

Key words: streptozotocin, natural killer, T-regulatory, interleukin 2, BALB/c mice.

(Cent Eur J Immunol 2020; 45 (4): 382-392)

\section{Introduction}

Diabetes mellitus (DM) is an autoimmune disease characterized by hyperglycemia accompanied by disturbance in the metabolism of carbohydrates, proteins and also lipids [1]. It has been predicted that the prevalence of diabetes would be raised worldwide from 177 million in 2000 to 370 million in 2030 [2]. In Egypt, the prevalence rate of type 1 DM (T1D) among school children in Cairo was 1.09/1000 [3].

In humans, diabetes mellitus is one of the most prevalent conditions with spontaneous manifestations [4]. In animals, T1D can be induced by the administration of diabetogenic inducing drugs such as streptozotocin, alloxan and anti-insulin serum. These agents selectively destroy the Langerhans islet $\beta$-cells [5]. The initiation of T1D requires both $\mathrm{CD} 4^{+} \mathrm{T}$ cells that are insulin reactive and $\mathrm{CD}^{+} \mathrm{T}$ cells that play a major role as $\beta$-cell killers [6]. In addition, B cells, natural killer (NK) cells, natural killer T cell (NKT), $\gamma \delta \mathrm{T}$ and macrophages participate in T1D disease progression [7].

NK cells play an important role in direct killing of target cells that are transformed or infected by certain microorganisms [8]. The natural cytotoxicity receptors include NKp46, NKp30, and NKp44 that are expressed on NK cells [9]. NK cells appeared in the pancreas when insulitis progressed to T1D and NKp46 engagement by beta cells lead to degranulation of NK cells [10]. Injection of soluble NKp46 proteins into non-obese diabetic mice during the early phase of insulitis and the pre-diabetic stage prevent the development of T1D [11]. These findings demonstrate that NKp46

Correspondence: Salma Aboelnazar, Department of Immunology and Allergy, Medical Research Institute, Alexandria University, Mousta Maher Gleem, 1234, Alexandria, Egypt, e-mail: mai.mouaz@alexu.edu.eg Submitted: 26.02.2019; Accepted: 13.12.2019 
has a great role in T1D and highlights potential new therapeutic modalities for this disease.

Regulatory T cells (Tregs) were first described as suppressors of antigen-activated immune responses to self and non-self-antigens [12]. Several markers for Tregs, such as human transcription factor forkhead box P3 (FoxP3), CTLA-4, CD25 and CD127 have been implicated [13]. FoxP3 could be most essential for the development and the maintenance of their suppressive function [14]. Mutations and disruptions of the Foxp3 regulatory pathway lead to organ-specific autoimmune diseases such as T1D [15].

Interleukin 2 (IL-2) is mainly secreted by activated T cells and, to a lesser extent by activated dendritic cells, natural killer (NK) cells, NKT cells, as well as B cells [16]. NK cells and T cells constitutively express receptors (CD122 and CD132), by which they respond to high-dose IL-2 and been activated [17]. Tregs constitutively express the high-affinity receptor for IL-2 (CD25), while this expression on other subsets of $\mathrm{T}$ cells is induced merely after activation. Therefore, in the steady state, Tregs respond better to IL-2 than other T cells [18]. This is why low dose IL-2, hypothetically, would preferentially increase Tregs numbers without causing overall immune activation [19]. In fact, Tregs activation has been linked to IL-2 administration in mice and a short course of low-dose IL-2 administration can reverse established disease [20].

Malek and colleagues reported that Tregs from normal individuals were invariably better responders to IL-2 followed by NK cells and memory $\mathrm{T}$ cells. Further work is needed to determine heterogeneity of responsiveness to low-dose IL-2 in Tregs as well as other IL-2-responsive cells, especially NK cells [21].

Chitosan is a polymer that is either partially or fully deacetylated chitin. It has been investigated extensively as a potential drug carrier due to its biocompatible characteristics. Therefore, it has been used widely in the medical field [22]. Studies recommended its use to coat other material nanoparticles to increase their bioavailability and decrease their impact on the body [23].

We intended in the present work to evaluate the modulatory effect of low dose IL-2 loaded chitosan nanosphere on NKp46 expressing natural killer cells and to compare this to its effect on foxp-3 expressing T regulatory cells in diabetic male inbreed Balb/c mice.

\section{Material and methods}

\section{Experimental animals}

A total of 116 BALB/c mice (10-12 weeks old and 20-25 grams weight), were housed in polycarbonate cages inside a well-ventilated room. Each cage contained not more than 5 mice. They were maintained under standard laboratory conditions of temperature $\left(22^{\circ} \mathrm{C}\right)$ with light/ dark cycles of 12 hours each where mice had free access to water and pellet diet. The streptozotocin (STZ)induced diabetic mice were fasting overnight before the start of the experiment [24]. All procedures were performed in accordance with regulations of Medical Research Institute guide for the care and the use of laboratory animals and after the acceptance of the Ethical Committee of the Alexandria University. Mice were purchased from the animal house of the Medical Technology Center, in Medical research institute, Alexandria University. The study was conducted from January to August 2018.

Mice were divided into five groups:

- Group I: includes 51 mice induced for T1D, injected with murine recombinant IL-2 loaded into chitosan nanoparticles;

- Group II: includes 21 mice induced for T1D, injected with murine recombinant IL-2;

- Group III: includes 20 mice induced for T1D, injected with empty chitosan particles;

- Group IV: includes11 mice induced for T1D not injected with any formulation as first control group. (control 1: diabetic mice);

- Group V: includes 8 mice free from T1D as a second control group (control 2: non-diabetic mice).

\section{Type 1 diabetes mellitus induction protocol}

T1D was experimentally induced according to the protocol described by Brosius [25]. Filtered sterilized cold Citrate buffer was added to Streptozocin (STZ) $9200 \mu \mathrm{l} / \mathrm{mg}$ ) (STZ, SIGMA, Germany) to a concentration of $5 \mathrm{mg} / \mathrm{ml}$. Citrate buffer $(0.1 \mathrm{M}): 2$ part of sodium citrate $(0.1 \mathrm{M})$ and 3 part of citrate acid $(0.1 \mathrm{M}), \mathrm{pH}$ adjusted to 4.0 by using $\mathrm{NaOH}(1 \mathrm{~N})$. Intraperitoneal injection of streptozotocin ( $200 \mathrm{mg} / \mathrm{kg}$ body weight (bw) was used, divided into 5 consecutive daily doses of $40 \mathrm{mg} / \mathrm{kg}$ bw each. Negative control mice received freshly prepared sodium citrate buffer by the same route.

Blood from retro-orbital sinus of all mice were collected for assessment of glucose and insulin level. Blood glucose was done by glucometer $(\mathrm{mg} / \mathrm{dl})$ while insulin level $(\mathrm{pmol} / \mathrm{l})$ was measured by enzyme-linked immunosorbent assay (ELISA).

\section{Preparation of IL-2 loaded chitosan nanoparticles}

Low molecular weight chitosan (48 kDa) derived from shrimp shells (Pandalus borealis), was purchased from Primex Co (Iceland]. Interleukin-2 was provided in the form of $200 \mu \mathrm{g} / \mathrm{ml}$ liquid, purchased from BioLegend Company (Netherlands). Chitosan nanoparticles (CSNPs) free or loaded with IL-2 were prepared by ionic gelation method. One $\mathrm{mg} / \mathrm{ml}$ of low molecular chitosan was dissolved in $1 \%(\mathrm{w} / \mathrm{v})$ acetic acid and sonicated before the solution become transparent. Triphenyl phosphate (TPP] solution $(1 \mathrm{mg} / \mathrm{ml})$ was added drop wise to $\mathrm{CS}$ solution $(\mathrm{pH}=5)$, under continuous stirring at 600 rotation per minute (rpm) for 30 minutes at room temperature. CSNPs spontaneously form via the electrostatic attraction between positively charged primary amino groups on chitosan chains and reversely charged polyanions (from TPP).

Recombinant murine interleukin 2 loaded chitosan nanoparticles were prepared according to Bertohold et al. [26]. Recombinant IL-2 with different concentration (0.05-0.1 and $0.33 \mu \mathrm{IU})$ were added to sodium sulfate solution $(20 \% \mathrm{w} / \mathrm{v})$. Sodium sulfate solution containing murine recombinant IL-2 was dropped into the acidic chitosan solution and stirred at $500 \mathrm{rpm}$ for $1 \mathrm{~h}$. The resulting opalescent suspension was determined as IL-2 loaded chitosan nanoparticles. Reaction mixture was centrifuged at $15000 \mathrm{rpm}$ at $4^{\circ} \mathrm{C}$ for $15 \mathrm{~min}$. The supernatant was decanted and nanoparticles were suspended in sterile distilled water and centrifuged at 15000 rpm at $4^{\circ} \mathrm{C}$ for $15 \mathrm{~min}$ to separate the nanoparticles. 

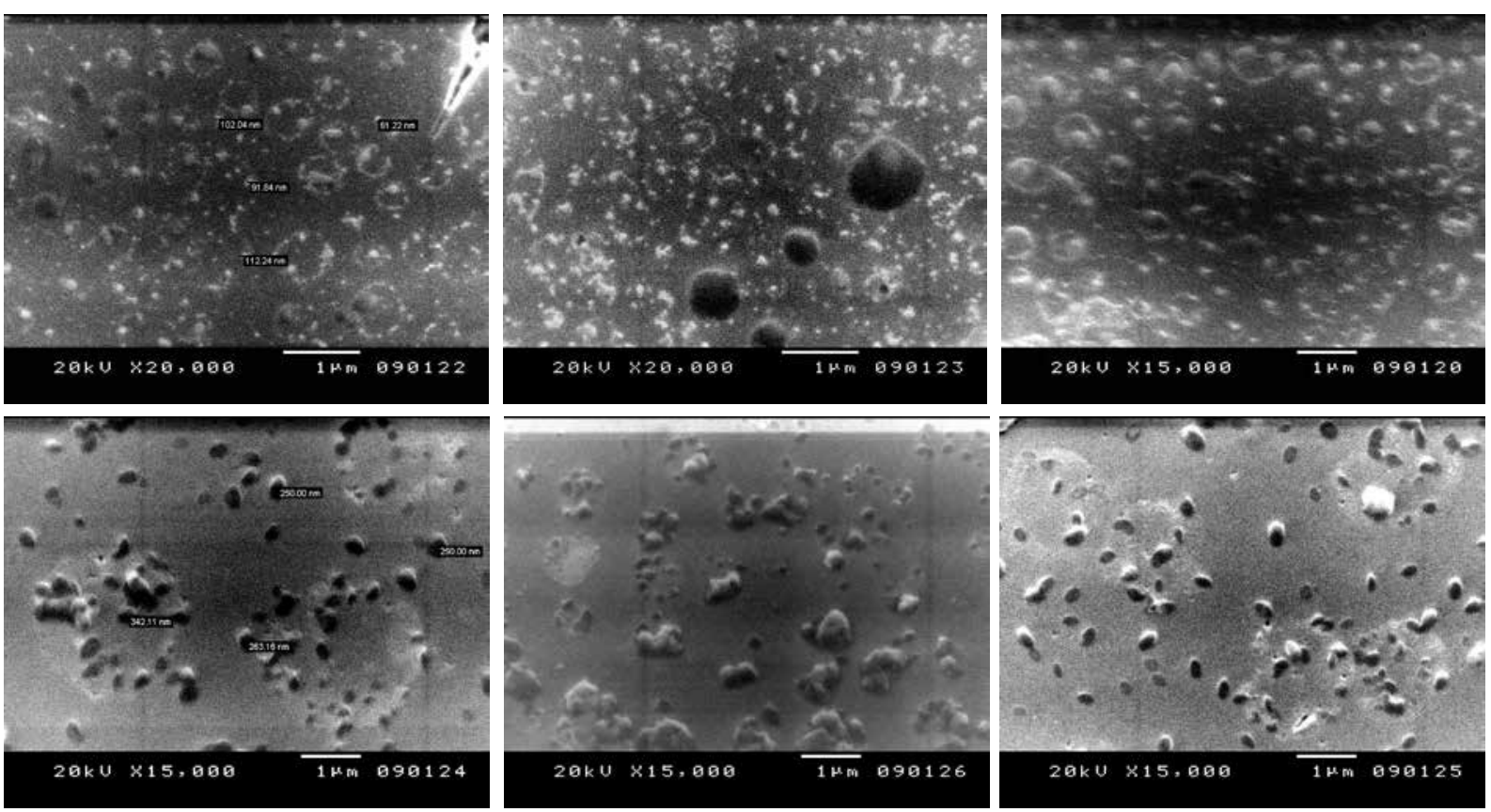

Fig. 1. Scanning electron microscope images: showing CSNPs in the upper part of the figure with spherical porous morphology with average diameter of $91.835 \mathrm{~nm}$. Lower part of the figure shows images for CSNPs loaded with IL-2 (spherical porous morphology with average diameter of $276.3175 \mathrm{~nm}$

IL-2 encapsulation efficiency of chitosan NP was determined by measuring the difference between the amount of protein incorporated in the nanoparticles preparation medium and the amount of non-entrapped protein remaining in the aqueous medium after the encapsulation process. Protein content in the supernatant was spectrophotometrically determined by universal protein content assay. Characterization of nanospheres was done using scanning electron microscope [27] (Fig. 1), furious transmission Infra-Red (Fig. 2) [28] and Zetasizer [29]. IL-2 loading and encapsulation efficacy of the nanoparticles was around $97 \%$.

\section{IL-2 loaded chitosan injection protocol}

Following STZ injection (40, 45 or $50 \mathrm{mg} / \mathrm{kg} / \mathrm{day})$, IL-2 loaded onto chitosan was prepared with actual dose of $0.05,0.1$ and $0.3 \mu \mathrm{IU}$ divided into 5 consecutive days administrated by subcutaneous injection according to protocol of klatzmann Abbas [30]. Mice were sacrificed at day 7, 14 and 21 following IL-2/chitosan administration.

\section{Short term culture}

Spleens were removed and collected into Petri dishes (7.5 $\times 1.5 \mathrm{~cm}$; Biosystem S.A., Spain), washed with $1 \mathrm{ml}$ phosphate buffer saline (PBS) $(\mathrm{pH}=7.2)$ then squeezed. PBS was added to cells and centrifuged at 2,000 rpm for 3 minutes. Cell pellet was resuspended, counted and adjusted to $1 \times 10 \% \mathrm{ml}$ in $4 \mathrm{ml}$ complete tissue culture medium composed of RPMI-1640 supplemented with L-glutamine, $10 \%$ heat-inactivated fetal calf serum, penicillin (100 IU/ml) and streptomycin $(100 \mu \mathrm{g} / \mathrm{ml})$. Splenocytes were maintained in a short-term culture (48 hours) stimulated with $10 \mu$ of Concavalin A
(Con A) (plant mitogen, known for its ability to stimulate mouse T-cell subsets) (Dwyer et al.). Details of the tissue culture protocol were adopted from the standard method developed by Davis [31].

\section{NK and Treg cells expression}

Assessment of NK and Treg cells was done using both flow cytometry (Cytomics FC500 flow cytometer) and ELISA. Monoclonal antibodies (mab) were purchased from (eBioscience, San Diego, CA), anti-CD3-FITC, anti-CD4-PE and anti-CD25-FITC or anti-CD56-PE. The frequency of each cell subset was calculated based on the percentage of positive cells in the total lymphocyte gate. For intracellular staining, cells were first labeled with relative marker, fixed, and permeabilized using a fix/perm kit according to the manufacturer's instructions and then labeled with anti-FOXP3PE or anti-NKp46-PE mab (PCH101; eBioscience).

NKp46 and Foxp3 were measured also in cell lysate by sandwich ELISA for in vitro quantitative measurement (mybiosource. com/prods/ELISA-Kit/mouse/forkhead-box-P3, NKp46). Following cell culture of mouse spleen Cells, repeated freezing and thawing cycles were done to damage cells and let out the inside components of the cell then Centrifugation at 2000-3000 RPM for approximately 20 minutes was done. The supernatants were collected carefully and centrifuged again when sediments occurred during storage.

\section{In vitro suppressor assay}

YAC-1 responder cells (ATCC ${ }^{\circledR}$ TIB $160^{\mathrm{TM}}$ ) acquired from Medical Technology Center in Alexandria University, were co-cultured with isolated NK cells in the absence or presence of Tregs 
A

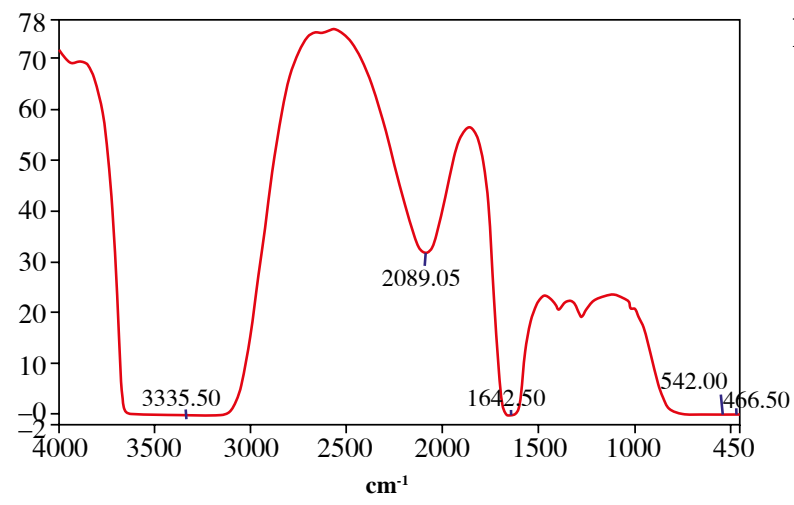

B

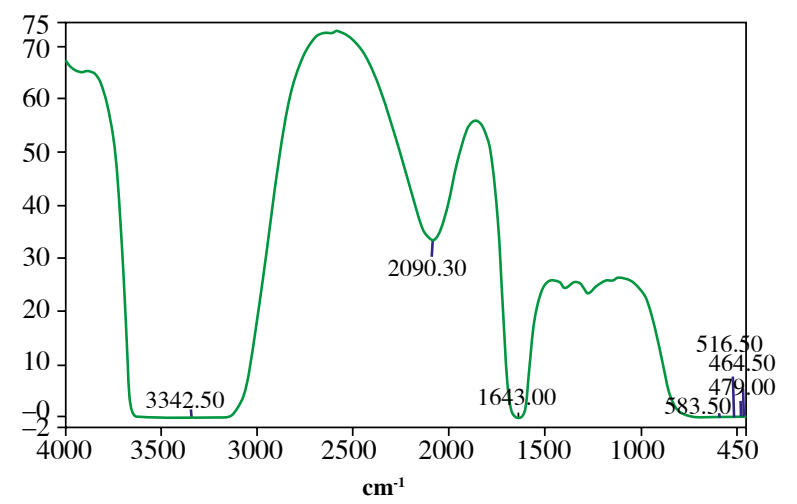

C

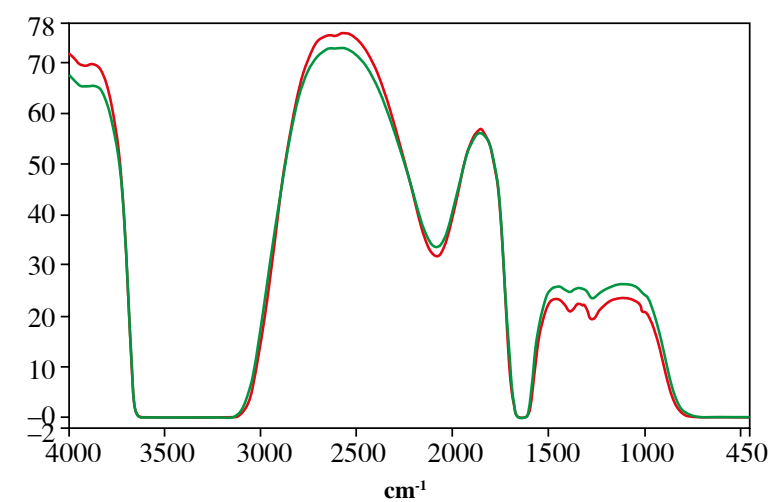

Fig. 2. FT-IR spectrum of Chitosan using FT-IR spectroscopy (Shimadzu, FT-IR-8400S, Japan). A) The stretching vibration of $\mathrm{OH}$ and NH2 groups is centered at $3335.60 \mathrm{~cm}-1$ for CSNPs , the peaks at $2089.05 \mathrm{~cm}-1$ with C-H stretching vibration for CSNPs, $\mathrm{C}=\mathrm{O}$ vibration appears at $1642.50 \mathrm{~cm}-1$ of acetyl groups in chitosan. The peaks around $542 \mathrm{~cm}-1$ correspond to saccharide structure of chitosan. B) The stretching vibration of $\mathrm{OH}$ and NH2 groups is centered at $3342.5 \mathrm{~cm}-1$ (steady state) for CSNPs loaded with IL-2, the peaks at $2090.30 \mathrm{~cm}-1$ with C-H stretching vibration for CSNPs loaded with IL-2, C=O vibration appears at $1643 \mathrm{~cm}-1$ in CSNPs loaded with IL-2. The peaks around $5583.50 \mathrm{~cm}-1$ for CSNPs loaded with IL-2). C) The two curves are almost identical indicates no change in characters between of CSNPs and CSNPs loaded with IL-2

$\left(\mathrm{CD} 4^{+} \mathrm{CD} 25^{+}\right)$cells to study the suppressive activity of Tregs. One million of responder cells were labeled by incubating cells with $100 \mathrm{mCi} 51 \mathrm{Cr}$ for $90 \mathrm{~min}$ at $37^{\circ} \mathrm{C}$, washing them three times with PBS, and seeding them at $10^{4}$ cells/well in round-bottom $96-$ well plates. The previously isolated NK cells were added to each well and cultured together at a ratio of $1: 0.5$, respectively, in RPMI-1640 complete culture medium. After $4 \mathrm{~h}$ incubation, 100-ml volumes of supernatant were collected and the amount of $51 \mathrm{Cr}$ released was measured using a g counter. NK cells were harvested and assessed for IFN- $\gamma$ production by ELISA and percentage of responder cells killing. IFN- $\gamma$ levels were estimated using commercial ELISA (Quantikine R\&D system, ELISA kit, USA) according to manufacturer recommendation [32].

\section{Statistical analysis}

All analyses were performed using SPSS software (SPSS for windows, version 21.0, Chicago, IL, USA) [33]. The test of normality was done using D'Agstino test. Quantitative data were described using mean and standard deviation for normally distributed data while abnormally distributed data was expressed using median, minimum and maximum. For normally distributed data, comparison between populations was done using t-test and (ANOVA) \& Pearson correlation coefficient. For abnormally distributed data, Mann-Whitney test and Spearman correlation were used. $p$-value smaller than 0.05 or 0.01 indicates statistical significance.

\section{Results}

\section{Animal grouping and characteristics}

An independent biostatistician (Graphpad Software) was used to calculate sample sizes. The analyses were predetermined (protocol-specific). The present study included 107 mice (93\%) used as a model for experimental T1D and 8 (7\%) as negative controls. One week following diabetes induction, fifteen diabetic mice were left without any treatment and represented the positive control group. Another 20 (17\%) diabetic mice were treated with empty chitosan nanoparticles and $21(18 \%)$ were treated with free IL-2 at concentrations of $0.05,0.1$ and $0.3 \mathrm{uIU} / \mathrm{ml}$. Another 51 (44\%) diabetic mice were treated with the same concentrations of murine recombinant IL-2 loaded into chitosan nanoparticles. At weekly intervals after IL-2 treatment, mice from all groups under study were sacrificed. 
Blood glucose level was monitored once before and daily after STZ injection until a diabetic status was confirmed. Insulin levels were also measured and used in parallel to animal weight to monitor the diabetic status of mice (data not shown).

\section{Effect of different formulations on the expression of NK cells and NKp46}

NK cells show significant changes in number in different animal groups (Fig. 3). As we noticed, mice induced for T1D had high-

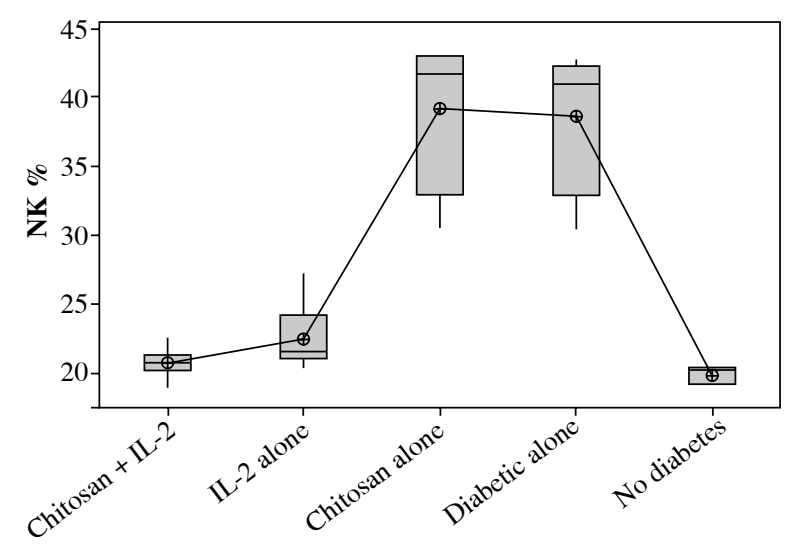

Fig. 3. NK cell expression in different groups. Data showed as percentage of expression by FACS. Group I: chitosan + IL-2 represented by 51 diabetic mice treated with chitosan + IL-2 (0.3) $\mu \mathrm{IU}$, Group II represented by 21 diabetic mice treated with IL-2 alone $(0.3) \mu \mathrm{IU}$, Group III represented by 20 diabetic mice treated with chitosan alone (empty chitosan), Group IV represented by 11 diabetic mice and Group V represented by 8 non-diabetic mice

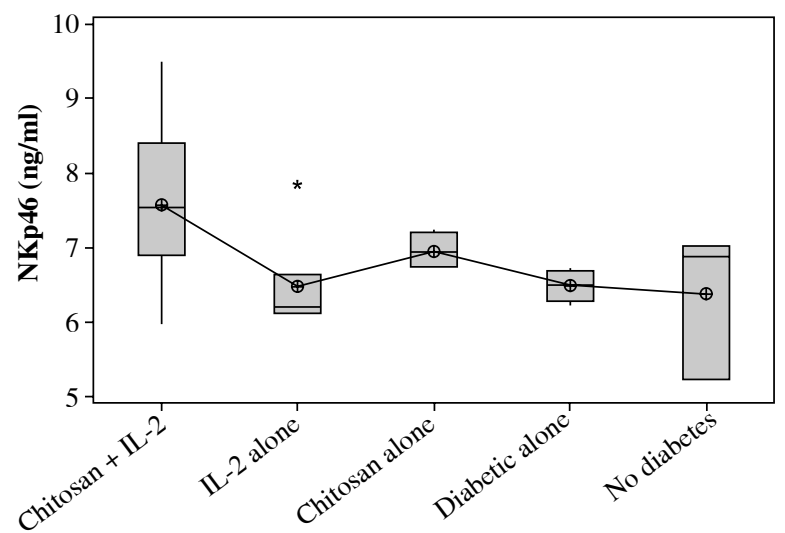

Fig. 4. NKp46 in cell lysate in different groups. Data showed as (ng/ml) by ELISA. Group I: chitosan + IL-2 represented by 51 diabetic mice treated with chitosan + IL-2 (0.3) $\mu \mathrm{IU}$, Group II represented by 21 diabetic mice treated with IL-2 alone (0.3) $\mu$ IU, Group III represented by 20 diabetic mice treated with chitosan alone (empty chitosan), Group IV represented by 11 diabetic mice and Group V represented by 8 non-diabetic mice er numbers of $\mathrm{NKp} 46^{+} \mathrm{NK}$ cells (mean $\pm \mathrm{SD}=38.7 \pm 5.66 \%$ ) and had no significant difference from those mice injected with empty chitosan nanoparticles (mean $\pm \mathrm{SD}=39.20 \pm 6.02 \%)(p=0.999)$. A significant decrease in NK expression was seen in mice injected with low dose IL-2 (mean $\pm \mathrm{SD}=22.43 \pm 2.47 \%$ ) or low dose IL-2 loaded in chitosan nanoparticles (mean $\pm \mathrm{SD}=22.43 \pm 2.47 \%$ ) with no statistical difference between the latter and the non-diabetic group (mean $\pm \mathrm{SD}=19.823 \pm 0.652 \%)(p=0.988)$.

On the other hand a significant increase in cell lysate NKp46 expression was seen in mice injected with IL-2 loaded chitosan than other groups. However, a significant NKp46 expression reduction was noticed in mice injected with low dose IL-2 alone $(p=0.01)$ (Fig. 4).

\section{Effect of changes of doses of IL-2 loaded chitosan on NK cell and NKp46 expression}

We used three different doses of IL-2 loaded chitosan injections $(0.05,0.1$ and $0.3 \mu \mathrm{IU})$. A highly statistical reduction in NK cell expression was noticed in mice injected with $(0.3) \mu \mathrm{IU}(p=$ 0.00 ). A non-significant difference was shown between the two other doses ( $p=0.901)$ (Fig. 5). For NKp46 expression in cell lysate, a statistical elevation was noticed in mice injected with $(0.1) \mu \mathrm{IU}$ and a significant reduction was seen in mice injected with (0.05) $\mu I U$ (Fig. 6).

\section{Effect of duration of treatment with IL-2 loaded chitosan (0.3 $\mu \mathrm{IU})$ on NK cell and NKp46 expression}

Our results showed a decrease in NK cell expression in the mice injected for three weeks with the dose $(0.3 \mu \mathrm{IU})$ of chitosan loaded with IL-2 (mean \pm SD $=18.537 \pm 0.584 \%$ ) but this reduction was not statistically significant between the three groups with different durations $(p=0.105)$ as shown in Figure 7.

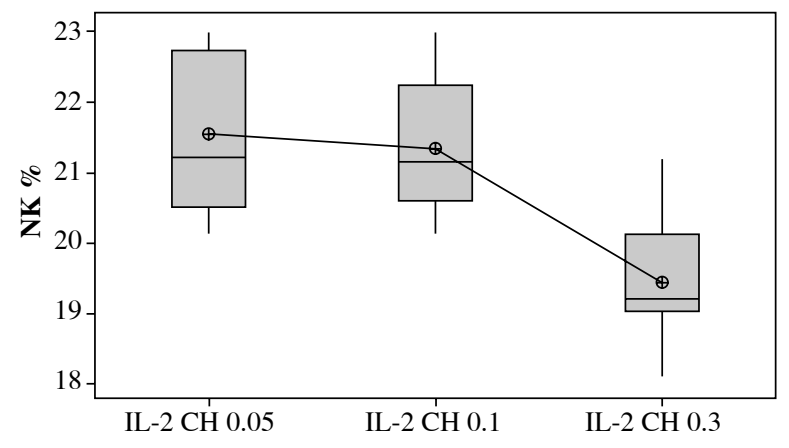

Fig. 5. Effect of changes of doses of IL-2 + chitosan on NK cell expression. Data showed as percentage of expression by FACS. Group I: chitosan + IL-2 (0.05) $\mu$ IU represented by 17 diabetic mice treated with chitosan + IL-2 (0.05) $\mu \mathrm{IU}$, Group II represented by 17 diabetic mice treated with chitosan + IL-2 (0.1) $\mu$ IU, Group III represented by 17 diabetic mice treated with chitosan + IL-2 (0.3) $\mu \mathrm{IU}$ 


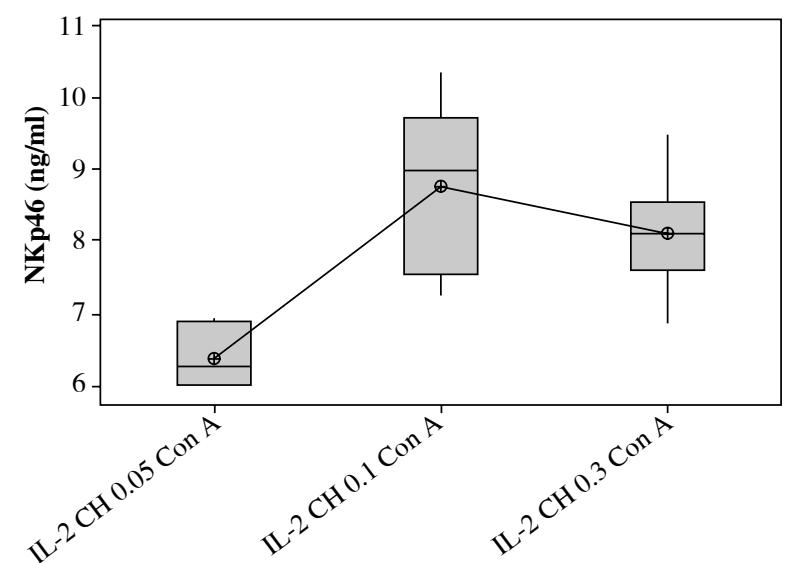

Fig. 6. Effect of changes of doses of IL-2+chitosan on NKp46 in cell lysate in different groups. Data showed as (ng/ml) by ELISA. Group I : chitosan + IL-2 (0.05 $\mu \mathrm{IU})$ represented by 17 diabetic mice treated with chitosan + IL-2 $(0.05 \mu \mathrm{IU})$, Group II represented by 17 diabetic mice treated with chitosan + IL-2 $(0.1 \mu \mathrm{IU})$, Group III represented by 17 diabetic mice treated with chitosan + IL-2 $(0.3 \mu \mathrm{IU})$

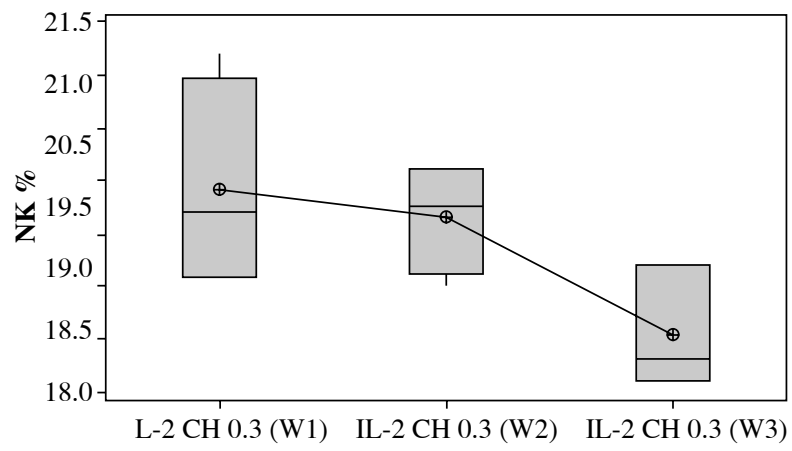

Fig. 7. Effect of duration of treatment with IL-2 loaded chitosan (0.3) $\mu \mathrm{IU}$ on NK cell expression in the three weeks. Data showed as percentage of expression by FACS. Group I: chitosan + IL-2 $(0.3 \mu \mathrm{IU})$ represented by 7 diabetic mice treated for one week, Group II represented by 6 diabetic mice treated with chitosan + IL-2 $(0.3 \mu \mathrm{IU})$ for two weeks, Group III represented by 6 diabetic mice treated with chitosan + IL-2 $(0.3 \mu \mathrm{IU})$ for three weeks

\section{Expression of Foxp3}

Both Treg cells percentage and cell lysate Foxp3 [ng/ml] were significantly highly expressed in mice injected with IL-2 loaded chitosan than other mice groups (Figs. 8 and 9).

Our results showed a significantly statistical difference elevation with $(0.3 \mu \mathrm{IU})$ doses as shown in Figure 10. This elevation was the highest in the third week (Fig. 11).

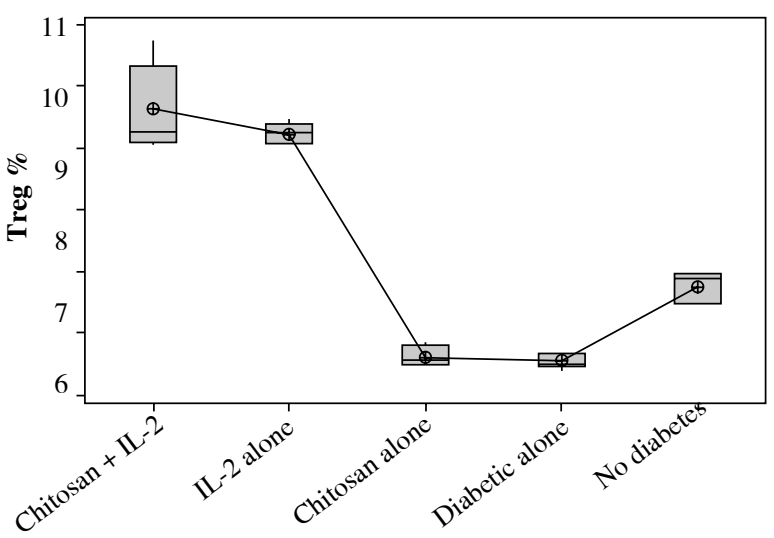

Fig. 8. Treg cell expression in different groups. Data showed as percentage of expression by FACS. Group I: chitosan + IL-2 represented by 51 diabetic mice treated with chitosan + IL-2 $(0.3 \mu \mathrm{IU})$, Group II represented by 21 diabetic mice treated with IL-2 alone ( $0.3 \mu \mathrm{IU})$, Group III represented by 20 diabetic mice treated with chitosan alone (empty chitosan), Group IV represented by 11 diabetic mice and Group V represented by 8 non-diabetic mice

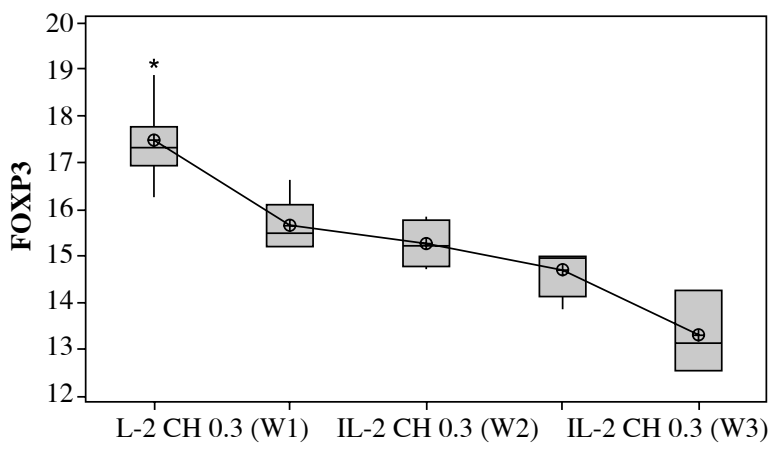

Fig. 9. Foxp3 in cell lysate in different groups. Data showed as (ng/ml) by ELISA. Group I: chitosan + IL-2 represented by 51 diabetic mice treated with chitosan + IL-2 $(0.3 \mu \mathrm{IU})$, Group II represented by 21 diabetic mice treated with IL-2 alone $(0.3 \mu \mathrm{IU})$, Group III represented by 20 diabetic mice treated with chitosan alone (empty chitosan), Group IV represented by 11 diabetic mice and Group V represented by 8 non-diabetic mice

\section{Correlation between Treg and NK expression in low dose IL-2 loaded chitosan ( $0.3 \mu \mathrm{IU})$ injected mice}

A statistical significant inverse correlation was found between Treg and NK cell expression in mice treated with IL-2 loaded chitosan with low dose $(0.3 \mu \mathrm{IU})(r=-0.473, p=0.041)$ (Fig. 12). 


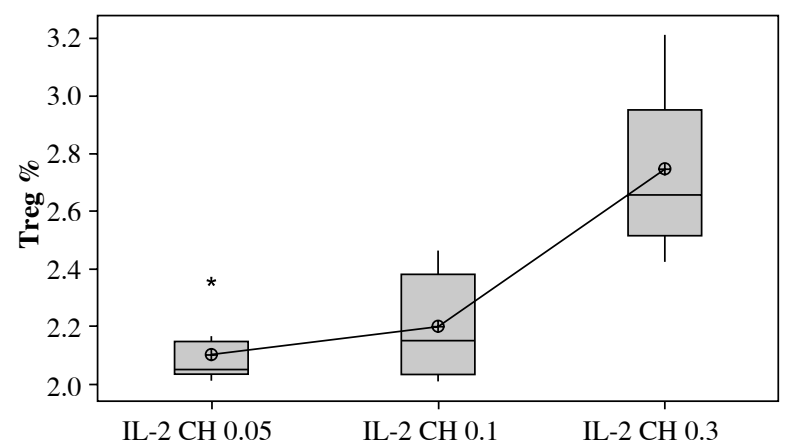

Fig. 10. Effect of changes of doses of IL-2+chitosan on Treg cell expression. Data showed as percentage of expression by FACS. Group I: chitosan + IL-2 (0.05 $\mu \mathrm{IU})$ represented by 17 diabetic mice treated with chitosan + IL-2 $(0.05 \mu \mathrm{IU})$, Group II represented by 17 diabetic mice treated with chitosan + IL-2 $(0.1 \mu \mathrm{IU})$, Group III represented by 17 diabetic mice treated with chitosan + IL-2 (0.3 $\mu \mathrm{IU})$

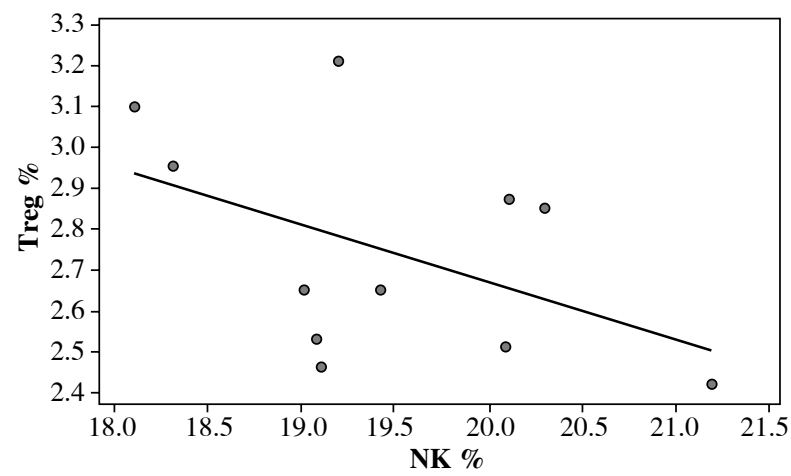

Fig. 12. Significant correlation between Treg and NK cell expression in mice treated with IL-2 loaded chitosan with low dose $(0.3 \mu \mathrm{IU})(r=-0.473, p=0.041)$

\section{NK cell functional assay}

Secretion of IFN- $\gamma$ by cultured NK cells with Treg cells in the culture supernatant showed significant decrease in those groups treated with chitosan loaded IL-2 $(p<0.00)$ (Fig. 13). This reduction was not significantly different between different doses $(p=$ $0.586)$ (Fig. 14). When we compare the dose ( $0.3 \mu \mathrm{IU})$ of chitosan loaded IL-2 in different duration of treatment, an insignificant difference also was found in the level of secreted IFN- $\gamma$ in the culture supernatant ( $p=0.839$ ) (Fig. 15).

The percentage of target cell killing was significantly lower in mice injected with (chitosan + IL-2) $(p<0.01)$ and between mice injected with this formulation and mice injected with IL-2 alone ( $p=0.043$ ) (Fig. 16). This impairment of killing ability was the significantly decreased with $(0.3 \mu \mathrm{IU})$ dose of chitosan $+\operatorname{IL}-2(p=0.006)$. However, a change in the duration of treatment with this dose does not show any significant difference

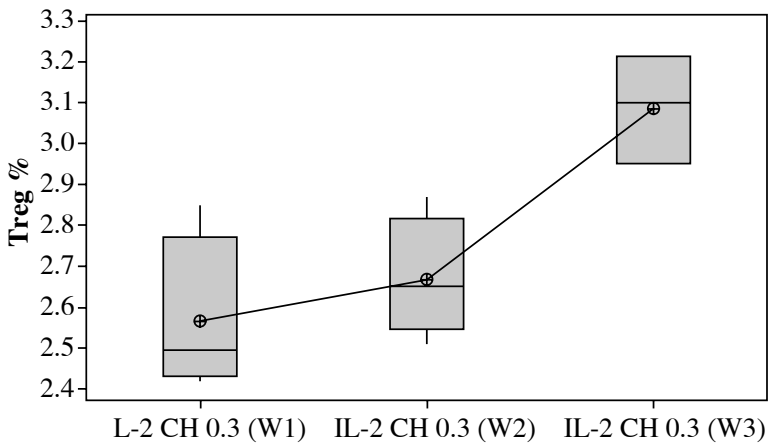

Fig. 11. Effect of duration of treatment with IL-2 loaded chitosan $(0.3 \mu \mathrm{IU})$ on Treg cell expression in the three weeks. Data showed as percentage of expression by FACS. Group I: chitosan + IL-2 ( $0.3 \mu \mathrm{IU})$ represented by 7 diabetic mice treated for one week, Group II represented by 6 diabetic mice treated with chitosan + IL-2 $(0.3 \mu \mathrm{IU})$ for two weeks, Group III represented by 6 diabetic mice treated with chitosan + IL-2 (0.3 $\mu \mathrm{IU})$ for three weeks

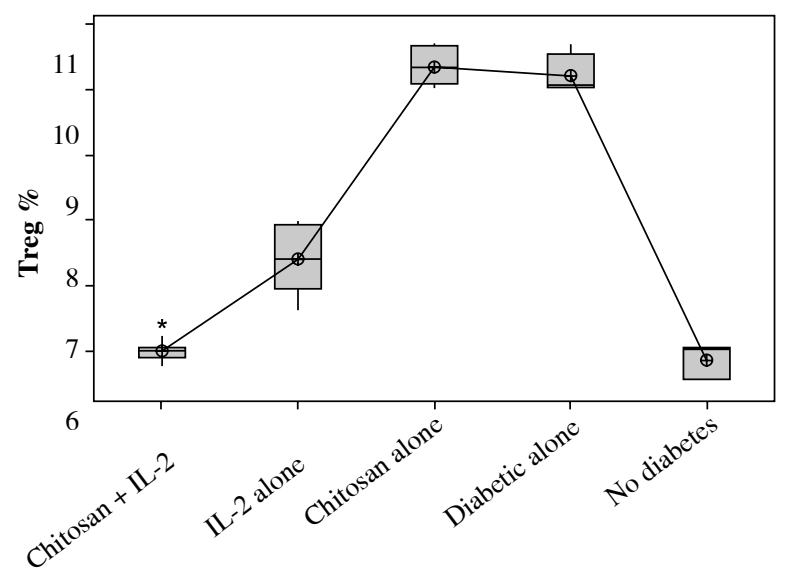

Fig. 13. IFN- $\gamma$ in cell supernatant of co-cultured NK+Treg in different groups. Data showed as (pg/ml) by ELISA. Group I: chitosan + IL-2 represented by 51 diabetic mice treated with chitosan + IL-2 (0.3 $\mu \mathrm{IU})$, Group II represented by 21 diabetic mice treated with IL-2 alone $(0.3 \mu \mathrm{IU})$, Group III represented by 20 diabetic mice treated with chitosan alone (empty chitosan), Group IV represented by 11 diabetic mice and Group V represented by 8 non-diabetic mice

between mice injected for one week (mean $\pm \mathrm{SD}=32.75 \pm 1.85 \%$ ) or two weeks (mean $\pm \mathrm{SD}=33.13 \pm 2.02)$ with $(0.3 \mu \mathrm{IU})(\mathrm{p}=0.954)$ (Fig. 17).

\section{Effect of different formulations on the glucose level and weight}

This was shown in Table 1 and Figure 18. 


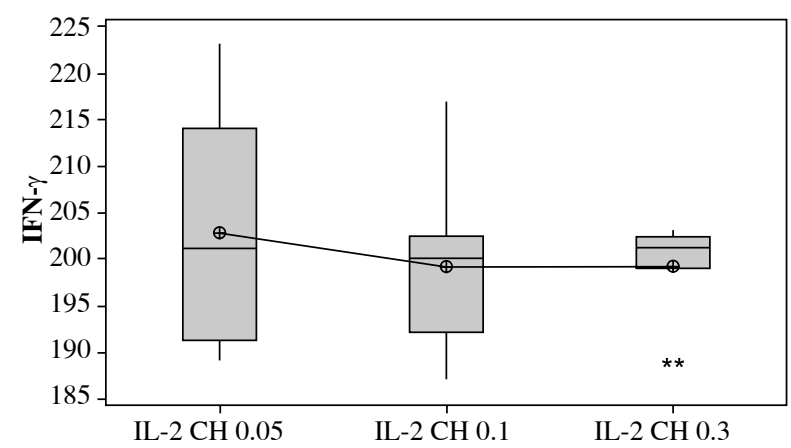

Fig. 14. Effect of changes of doses of IL-2+chitosan on IFN- $\gamma$ secretion in culture supernatent. Data showed as $(\mathrm{pg} / \mathrm{ml})$ by ELISA. Group I: chitosan + IL-2 $(0.05 \mu \mathrm{IU})$ represented by 17 diabetic mice treated with chitosan $+\mathrm{IL}-2(0.05 \mu \mathrm{IU})$, Group II represented by 17 diabetic mice treated with chitosan + IL-2 (0.1 $\mu \mathrm{IU})$, Group III represented by 17 diabetic mice treated with chitosan + IL-2 $(0.3 \mu \mathrm{IU})$

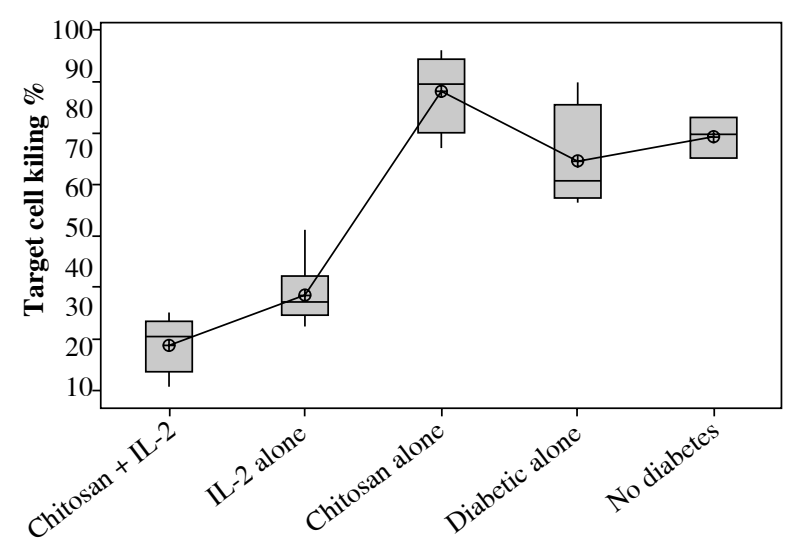

Fig. 16. Cytotoxicity suppression assay: Data show target cell killing in co-cultured NK+Treg in different groups. Data showed as percentage of killed cells. Group I: chitosan + IL-2 represented by 51 diabetic mice treated with chitosan + IL-2 (0.3 $\mu \mathrm{IU})$, Group II represented by 21 diabetic mice treated with IL-2 alone $(0.3 \mu \mathrm{IU})$, Group III represented by 20 diabetic mice treated with chitosan alone (empty chitosan), Group IV represented by 11 diabetic mice and Group V represented by 8 non-diabetic mice

\section{Discussion}

Autoimmune diabetes (type 1 diabetes) initiation and progression are primarily caused by Teff cells, but NKs have been identified in the pancreas of T1D patients and in experimental mouse models of T1D [34, 35]. At diabetes onset, there is an altered Teff/Treg ratio and increased IFN $\gamma$ production aggravating autoimmunity in pancreatic microenvironment which is correctable with low dose IL-2 [36].

Grinberg-Bleyer et al. stated the significant role of IL-2 in the non-obese diabetic mice (NOD) pancreatic microenvironment

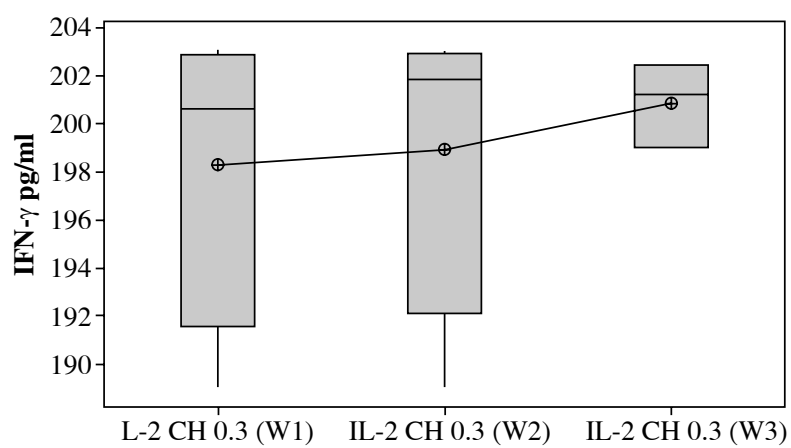

Fig. 15. Effect of duration of treatment with IL-2 loaded chitosan $(0.3 \mu \mathrm{IU})$ on IFN- $\gamma$ in cell supernatant of co-cultured NK+Treg in different groups. Data showed as percentage of expression by FACS. Group I: chitosan + IL-2 $(0.3 \mu \mathrm{IU})$ represented by 7 diabetic mice treated for one week, Group II represented by 6 diabetic mice treated with chitosan + IL-2 (0.3 $\mu \mathrm{IU})$ for two weeks, Group III represented by 6 diabetic mice treated with chitosan + IL-2 $(0.3 \mu \mathrm{IU})$ for three weeks

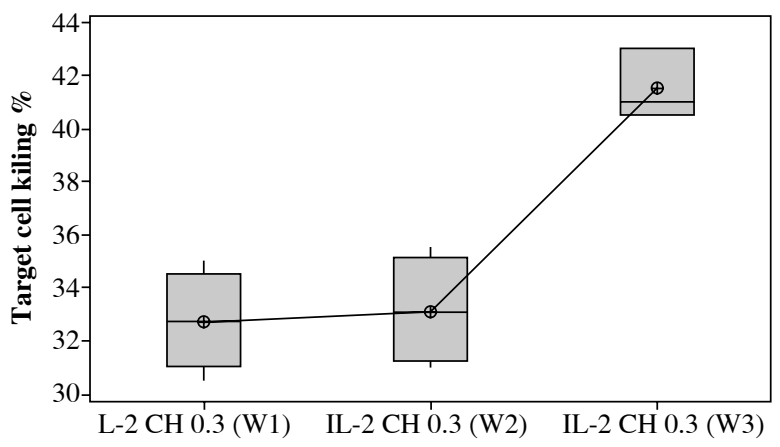

Fig. 17. Effect of duration of treatment with IL-2 loaded chitosan $(0.3 \mu \mathrm{IU})$ on suppressive ability of Treg on NK cell in co-cultures. Data show target cell killing in co-cultured $\mathrm{NK}+\mathrm{Treg}$ in different groups as percentage of killed cells. Group I: chitosan + IL-2 (0.3 $\mu \mathrm{IU})$ represented by 7 diabetic mice treated for one week, Group II represented by 6 diabetic mice treated with chitosan + IL-2 $(0.3 \mu \mathrm{IU})$ for two weeks, Group III represented by 6 diabetic mice treated with chitosan + IL-2 $(0.3 \mu \mathrm{IU})$ for three weeks

for Treg survival and function. The IL-2 pathway is impaired in NOD mice, and that is accompanied by decreased IL-2 levels [19]. There were suggestions that before the onset of the disease; Tregs consume predominantly IL-2, allowing for normal Treg numbers with appropriate Teff/Treg ratio. Perhaps, Tregs have a competitive advantage in this microenvironment based on their constitutive expression of IL-2Rs that is higher than that expressed on CD25-expressing NKs or on activated T cells [37].

Though, in the pancreatic microenvironment, the decrease in Tregs at disease onset might enable the accumulation of NKs. These 


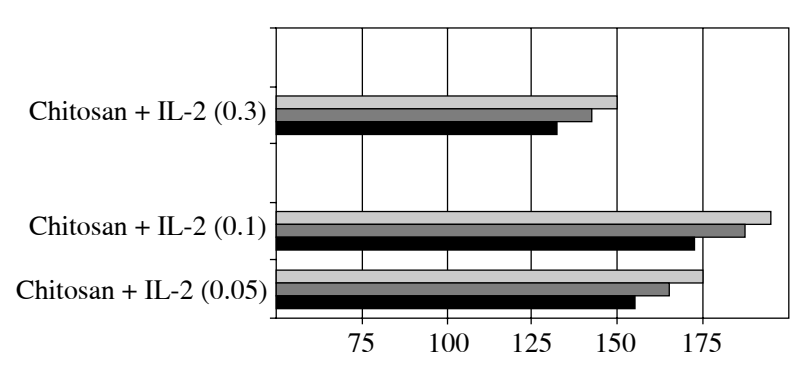

$\square$ Week 3 Mean + SD $\square$ Week 2 Mean + SD $\square$ Week 1 Mean + SD

Fig. 18. Effect of changes of doses of IL-2 + chitosan on glucose level

IFN $\gamma$-producing NKs become activated and aggravate autoimmunity by boosting the responses of autoreactive Teff [38], or if an exceedingly high doses of IL-2 are present [39]. Conversely, an appropriate low dose IL-2 could enhance Tregs and promote regulation on these proinflammatory NKs, which has not yet been studied.

Low-dose IL-2 was studied to selectively stimulate Tregs and their regulatory function. Data emerging from T1D trials with these autologous Tregs demonstrate the limitations of protocols that rely on expanded Tregs infusion without any recipient manipulation. The role of NKs in this context is not established and requires to be understood in order to improve therapeutic strategies aimed at resetting the balance between Teff and Tregs. However, there are contradictory reports about NK involvement in autoimmune diabetes models describing both protective and destructive functions.

Together with their role to contribute to an inflammatory environment, NKs respond to IL-2 and compete for IL-2 during early diabetes development in mice, hence impacting immune-based therapies. So, it is a necessity to unravel the correlations between NK and Treg cells to better understand the controversial role of NKs in diabetes. Thus, we intended at this work to study the regulatory effect of low dose IL-2 in experimentally induced diabetic mice, on NK cell in relation to Treg cell expression.

Unfortunately, a former prescription form of IL-2 (proleukin) has an explicit warning for exacerbation of a variety of autoimmune and inflammatory diseases [40]. Therefore, we created a new mode of delivering the low dose of IL-2 selectively to target cells by using chitosan nanoparticles. Chitosan has received growing attention mainly due to their ability to target specific delivery systems [41].

For this purpose we prepared three formulations of IL-2 with three low doses (0.05-0.1 and $0.3 \mu \mathrm{IU})$ loaded on chitosan nanosphere, and injected those at three weekly intervals in three groups of experimentally induced diabetic mice. Our main goal was to evaluate the effect of low dose IL-2 on NK cells as a novel mechanism to set the balance between them and Tregs. This evaluation of NK expression was designed to assess the expression of NK cell in splenocyres as well as the NKp46 level and the NK cell cytotoxicity.

The use of NKp46 marker for identification of bulk NKs would be a very accurate measure of NK. Furthermore, the surface expression of NKp46 was found to be conserved on NK cells across mammalian species. On this basis, NKp46 could be a con-
Table 1. Effect of treatment on glucose level and weight

\begin{tabular}{lcc}
\hline Characteristics & $\begin{array}{c}\text { Group I treated with } \\
\text { IL-2 loaded Chitosan }\end{array}$ & $\begin{array}{c}\text { Group II treated } \\
\text { with IL-2 }\end{array}$ \\
\hline$n$ & 51 & 21 \\
\hline $\begin{array}{l}\text { Glucose level } \\
\text { before treatment }\end{array}$ & $287 \pm 105$ & $275.3 \pm 90.0$ \\
\hline $\begin{array}{l}\text { Glucose level } \\
\text { after treatment }\end{array}$ & $145 \pm 46.3$ & $144.7 \pm 31.5$ \\
\hline$p 1$ & 0.0001 & 0.002 \\
\hline $\begin{array}{l}\text { Weight before } \\
\text { treatment }\end{array}$ & $24.88 \pm 4.67$ & $24.42 \pm 5.64$ \\
\hline $\begin{array}{l}\text { Weight after } \\
\text { treatment }\end{array}$ & $29.56 \pm 4.62$ & $27.12 \pm 5.85$ \\
\hline$p 2$ & 0.0001 & 0.098 \\
\hline
\end{tabular}

$n-$ number of each group separately, mean $+S D$ of weight, glucose level before and after STZ in the studied groups, $p 1$ - value between glucose level before and after treatment, p2 - value between weight before and after treatment

sistent marker to identify NK cells in different animal models. This comparison was not possible before because of the lack of a common and comprehensive receptor repertoire between dissimilar species [42].

We intended to compare the three doses of IL-2 to find the dose that has caused more NKP46 modulation at this new onset diabetes, then we monitored the statistical differences in levels of NKp46 and Foxp3 - as markers of NK and Treg cells activity respectively- from mice which are injected with other formulations including: IL-2 alone or chitosan alone.

Our observations revealed conflicting results between surface expression of NKp46 on NK cells and their secreted form in cell lysate. While a decrease in the expression of NKp46+ NK cells was noticed in mice treated with the low dose IL-2 loaded in chitosan. This reduction was significantly observed in dose $(0.3 \mu \mathrm{IU})$ and in mice treated for three weeks. This could be related to findings of Hirakawa et al., which revealed the indirect effects of prolonged exposure to low concentrations of IL-2 on NK cells in vivo [43].

On the other hand, an elevation in secreted level of NKp46 was observed in cell lysate in this group of mice. This could be explained by the findings of Ito et al. who found that NK cells are preferentially expanded by low dose IL-2 in a dose dependent manner but their most prominent expansion observed was at dose level of 200,000 IU/m [44]. Healthy humans express the ligand for the NKp46 receptor [34] and this could be impaired in diabetes. The expression of the NKp46 ligand is stable in functional $\beta$ cells and therefore $\beta$ cells are constantly at risk of being attacked by NKs through NKp46-stimulated activation. In vitro, incubation of NKs with $\beta$ cells leads to NK degranulation and $\beta$ cell killing. The NKp46 receptor was also found critical in diabetes development in vivo in low dose STZ-diabetes in B6 mice [45].

NK cell's killing and cytokine secretion ability showed an observed impairment when co-cultured with isolated Tregs. This suppressive capability of Treg was more prominent in mice treated with chitosan + IL-2 formulation. However, it showed no cor- 
relation to the dose or duration of this treatment. This indicates a critical role of Tregs in NK homeostasis, activation, and function, predominantly by controlling the availability of IL-2 in the microenvironment. Data from the Mathis group show that in the absence of Treg cells, NKs produce abundant IFN- $\gamma$ and contribute to the diabetic lesion in NOD mice. NKs were found to be initiators of autoimmune responses by stimulating CD4 T cells [46]. Additionally, IL-2 was the critical link between Treg and NKs in the pancreatic microenvironment [47].

Moreover, our results showed a statistical significant correlation between NKp46 and Foxp3 expression in IL-2 loaded chitosan receiving group of mice with low doses $(0.3 \mu \mathrm{IU})$. The maximum Foxp3 expression was observed at the dose $(0.3) \mu \mathrm{IU}$. This comes in non-accordance with Zorn et al. who found that the effect of IL-2 on Foxp3 expression in Tregs was detectable at concentrations as low as $0.1 \mathrm{U} / \mathrm{ml}$, which likely target the high-affinity receptor for IL-2 [48]. Also, in disagreement to our results, Tang et al. found that NOD mice treated with low dose of IL-2 in the form of a IL-2/anti-IL-2 mAb complex led no difference in expression of NK cells [49], but this is obviously due to the different formulation they used. In addition, Baeyens et al. found that administration of low-dose IL-2 alone or combined with rapamycin counteracted IL-2 effects on Treg cells, failed to control IL-2-boosted NK cells, and broke IL-2-induced tolerance in a reversible way [40].

Our group is working nowadays on comprehensive mapping to the IL-2 signaling network to further elucidate the molecular mechanisms of IL-2 that could facilitate the development of specific agonists and antagonists to efficiently modulate immune responses.

The authors declare no conflict of interest.

\section{References}

1. Hameed I, SR, Mir SA, et al. (2015): Type 2 diabetes mellitus: from a metabolic disorder to an inflammatory condition. World J Diabetes 6: 598-612.

2. Shaw JE, Sicree RA, Zimmet PZ (2010): Global estimates of the prevalence of diabetes for 2010 and 2030. Diabetes Res Clin Pract 87: 4-14.

3. El-Ziny MA, Salem NA, El-Hawary AK, et al. (2014): Epidemiology of childhood type 1 diabetes mellitus in Nile Delta, northern Egypt - a retrospective study. J Clin Res Pediatr Endocrinol 6: 9-15.

4. Pilla SJ, Balasubramanyam A, Knowler WC, et al. (2018): Islet autoantibody positivity in overweight and obese adults with type 2 diabetes. Autoimmunity 51: 408-416.

5. Jobim M, Chagastelles P, Salim PH, et al. (2010): Association of killer cell immunoglobulin-like receptors and human leukocyte antigen-C genotypes in South Brazilian with type 1 diabetes. Hum Immunol 71: 799-803.

6. Gur C, Porgador A, Elboim M, et al. (2010): The activating receptor NKp46 is essential for the development of type 1 diabetes. Nat Immunol 11: 121-137.

7. Ofer G, Rami Y, Gabriella F, et al (2015): $\alpha 1$-Antitrypsin modifies general natural killer cell interactions with dendritic cells and specific interactions with islet $\beta$-cells in favour of protection from autoimmune diabetes. Immunology 144: 530-539.
8. Ogasawara K, Hamerman JA, Ehrlich LR, et al. (2004): NKG2D blockade prevents autoimmune diabetes in NOD mice. Immunity 20: 757-767.

9. Srivastava BI, Srivastava MD (2006): Expression of natural cytotoxicity receptors NKp30, NKp44, and NKp46 mRNAs and proteins by human hematopoietic and non-hematopoietic cells. Leuk Res 30:37-46.

10. Denise L (2014): Why were we wrong for so long? The pancreas of type 1 diabetic patients commonly functions for decades. Diabetologia 57: 1-3.

11. Santamaria $P$ (2010): The long and winding road to understanding and conquering type 1 diabetes. Immunity 32: 437-445.

12. Kaur S, Mirza AH, Brorsson CA, et al. (2016): The genetic and regulatory architecture of ERBB3-type 1 diabetes susceptibility locus. Mol Cell Endocrinol 419: 83-91.

13. Jonsdottir B, Larsson C, Lundgren M, et al. (2018): Childhood thyroid autoimmunity and relation to islet autoantibodies in children at risk for type 1 diabetes in the diabetes prediction in skíne [DiPiS] study. Autoimmunity 51: 228-237.

14. Zhang Y, Bandala-Sanchez E, Harrison LC (2012): Revisiting regulatory $\mathrm{T}$ cells in type 1 diabetes. Curr Opin Endocrinol 19: 271-278.

15. Hori S, Nomura T, Sakaguchi S (2003): Control of regulatory $\mathrm{T}$ cell development by the transcription factor Foxp3. Science 299: 1057-1061.

16. Harris DP, Haynes L, Sayles PC, et al. (2000): Reciprocal regulation of polarized cytokine production by effector $\mathrm{B}$ and T cells. Nat Immunol 1: 475-482.

17. Tang Q (2015): Therapeutic Window of Interleukin-2 for Autoimmune Diseases. Diabetes 64: 1912-1913.

18. Corthay A (2009): How do Regulatory T Cells Work? Scand J Immunol 70: 326-336.

19. Grinberg-Bleyer Y, Baeyens A, You S, et al. (2010): IL-2 reverses established type 1 diabetes in NOD mice by a local effect on pancreatic regulatory T cells. J Exp Med 207: 1871-1878.

20. Shameli A, Yamanouchi J, Tsai S, et al. (2013): IL-2 promotes the function of memory-like autoregulatory CD8+T cells but suppresses their development via FoxP3+Treg cells. Eur J Immunol 43: 394-403.

21. Yu A, Snowhite I, Vendrame F, et al. (2015): Selective IL-2 responsiveness of regulatory $\mathrm{T}$ cells through multiple intrinsic mechanisms supports the use of low-dose IL-2 therapy in type 1 diabetes. Diabetes 64:2172-2183.

22. Sara P, Paul C, James S, et al. (2010): Novel biocompatible chitosan decorated single-walled carbon nanotubes [SWNTs] for biomedical applications: theoretical and experimental investigations. Phys Chem 12: 15636-15643.

23. Elgadir MA, Uddin MS, Ferdosh S, et al. (2015):Impact of chitosan composites and chitosan nanoparticle composites on various drug delivery systems: a review. J Food Drug Anal 23: 619-629.

24. BALB/c. Inbred strains of mice. Jackson Lab 2007; 4: 16.

25. Brosius F (2006): Low-dose streptozotocin induction protocol [Mouse]. Animal models of Diabetic Complication Consortium. Available at: https://www.diacomp.org/shared/showFile. aspx? doctypeid $=3 \&$ docid $=19$.

26. Berthold A, Cremer K, Kreuter J (1996): Preparation and characterization of chitosan microspheres as drug carrier for prednisolone sodium phosphate as model for anti inflammatory drugs. J Control Release 39: 17-25.

27. Guo L, Liu G, Hong RY, et al. (2010): Preparation and characterization of poly [acrylic acid] magnetic microspheres. Mar Drugs 8: 2212-2222. 
28. Lima I, Claudio A (2004): A thermodynamic investigation on chitosan-divalent cation interactions. Thermo Acta 421: 133-139.

29. Bhattacharjee S (2016): DLS and zeta potential - what they are and what they are not? J Control Release 235:337-51.

30. Klatzmann D, Abbas AK (2015): The promise of low-dose interleukin-2 therapy for autoimmune and inflammatory diseases. Nat Rev Immunol 5: 283-294.

31. Davis J (1995): Basic Cell Culture Technique: A Practical Approch. Oxford: Oxford University Press.

32. Tai1 LH, Tanese de Souza C, Makrigiannis AP, Auer RA. (2013): Ex vivo natural killer cell cytotoxicity assay. Bio-Protocol 3: 16.

33. Wellman B (1998): Doing It Ourselves: The SPSS Manual as Sociology's Most Influential Recent Book. In: Clawson D (ed.). Required Reading: Sociology's Most Influential Books. Amherst: University of Massachusetts Press; 71-78.

34. Dotta F, Censini S, van AG, et al. (2007): Coxsackie B4 virus infection of beta cells and natural killer cell insulitis in recent-onset type 1 diabetic patients. Proc Nat Acad Sci U S A 104: 5115-5120.

35. Gur C, Porgador A, Elboim M, et al. (2010):The activating receptor NKp46 is essential for the development of type 1 diabetes. Nat Immunol 11: 121-128.

36. Hulme MA, Wasserfall CH, Atkinson MA, et al. (2012): Central role for interleukin-2 in type 1 diabetes. Diabetes 61: 14-22.

37. Rosenzwajg M, Churlaud G, Mallone R, et al. (2015): Lowdose interleukin-2 fosters a dose-dependent regulatory $\mathrm{T}$ cell tuned milieu in T1D patients. Autoimmunity 58: 48-58.

38. Yu A, Snowhite I, Vendrame F, et al. (2015): Selective IL-2 responsiveness of regulatory $\mathrm{T}$ cells through multiple intrinsic mechanisms supports the use of low-dose IL-2 therapy in type 1 diabetes. Diabetes 64: 2172-2183.

39. Koga T, Mizui M, Yoshida N, et al. (2014): KN-93, an inhibitor of calcium/calmodulin-dependent protein kinase IV, promotes generation and function of Foxp3 [+] regulatory $\mathrm{T}$ cells in MRL/lpr mice. Autoimmunity 47: 445-450.

40. Baeyens A, Pérol L, Fourcade G, et al. (2013): Limitations of IL-2 and rapamycin in immunotherapy of type 1 diabetes. Diabetes 62: 3120-3131.

41. Abd Elgadir M, Salim MD, Sahena F, et al. (2015): Impact of chitosan composites and chitosan nanoparticle composites on various drug delivery systems. J Food Drug Anal 23: 619-629.

42. Hudspeth K, Silva-Santos B, Mavilio D (2013): Natural cytotoxicity receptors: broader expression patterns and functions in innate and adaptive immune cells. Front Immunol 4: 69.

43. Hirakawa M, Matos TR, Liu H, et al. (2016): Low-dose IL-2 selectively activates subsets of CD4+ Tregs and NK cells. JCI Insight 1: e89278.

44. Ito S, Bollard CM, Carlsten M, et al. (2014): Ultra-low dose interleukin-2 promotes immune-modulating function of regulatory $\mathrm{T}$ cells and natural killer cells in healthy. Mol Ther 22: 1388-1395.

45. Enk J, Mandelboim O (2014): The role of natural cytotoxicity receptors in various pathologies: emphasis on type I diabetes. Front Immunol 5: 4.

46. Feuerer M, Shen Y, Littman DR, et al. (2009): How punctual ablation of regulatory $\mathrm{T}$ cells unleashes an autoimmune lesion with in the pancreatic islets. Immunity 31: 654-664.

47. Sitrin J, Ring A, Garcia KC, et al. (2015): Regulatory T cells control NK cells in an insulitic lesion by depriving them of IL-2. J Exp Med 210: 1153-1165.
48. Zorn E, Nelson EA, Mohseni M, et al. (2006): IL-2 regulates FOXP3 expression in human CD4+CD25+ regulatory T cells through a STAT-dependent mechanism and induces the expansion of these cells in vivo. Blood 108: 1571-1579.

49. Tang Q, Adams JY, Penaranda C, et al. (2008): Central role of defective interleukin-2 production in the triggering of islet autoimmune destruction. Immunity 28: 687-697. 